\title{
Mutations and Linkage Groups in Japanese Strains of the Housefly
}

\author{
Masuhisa Tsuramoto, Yoko Baba and Sota Hiraga \\ Genetical Laboratory, Faculty of Science, Osaka University and \\ Department of Genetics, Osaka University Medical School, Osaka, Japan
}

Received February 6, 1961

It has been generally recognized that the extensive use of synthetic insecticides for pest control has resulted in the development of insecticide-resistance in insects of medical and agricultural importance. In order to overcome such a serious problem, co-operative investigation of the fundamentals is necessary from the practical standpoint. Genetical studies on insecticide-resistance in houseflies and mosquitoes by several pioneer workers have been based on the results obtained from reciprocal crosses between resistant and susceptible strains or from backcrosses of the $F_{1}$ hybrids to their parental strains. These studies have been skillfully reviewed by Milani (1956-7), Crow (1957) and Brown (1958). The deficiencies of the early work on the genetic mechanism of insecticide-resistance were mainly due to the lack of knowledge of basic genetics in the housefly. Therefore there is a present and urgent need to integrate fundamental information on housefly genetics to form a basis for further investigations on insecticide-resistance.

The first report on the formal genetics of the housefly appeared in the form of lists of several mutants contributed by Sarkissian and by Serebrovsky to the 15th issue of the Drosophila Information Service in 1941, though these reports were not considered as formal publication. Unfortunately, no extensive study was subsequently developed by these Russian investigators. However, investigation of the formal genetics of the housefly has been reopened by several insect geneticists in Italy, Japan and the U.S. A.

Milani (1954) has described 22 mutants of the housefly in Italy, and some of them were employed in the subsequent genetic analyses of DDT-resistance in this species. Knockdown-resistance to DDT was found to be inherited as a single recessive gene, $k d r$, which was linked with bwb (brown-body) and $d v$ (divergent) but not with ocra (ocra) (Milani, 1955, 1958; Milani and Travaglino, 1957). At the University of Kansas, U.S. A., the housefly genetics has also been initiated. Some mutant types. and aberrant forms of the housefly were reported by Sullivan and Hiroyoshi (1960). Recently, Hiroyoshi (1960) has studied 17 mutants of American houseflies and clas-

1) This study is supported in part by grants from the World Health Organization, U.N.N., and from the Scientific Research Fund of the Ministry of Education, Japan (No. 0031 in 1959 and No. 0035 in 1960). 
sified them into 5 linkage groups which are assumed to represent all the autosomes of the housefly.

Several years ago, study of the housefly genetics was concurrently attempted in Japan, and a part of the work was reported by Tsukamoto et al. (1957). Since 1958, isolation of mutant strains and performance of linkage tests with them have proceeded on a large scale in this laboratory. After the Japanese linkage groups had been established, certain important marker strains were obtained from the University of Kansas and compared with the Japanese strains for allelism and/or linkage in order to avoid further confusion or synonymy.

\section{Materials and Methods}

Samples taken in the field in 1958 from Hikone and from Akashi were used as: major source of mutations. Inbreeding of these strains for several generations resulted in the discovery of various kinds of morphological aberrations. Adult flies of each generation were anaesthetized with $\mathrm{CO}_{2}$ and ether, and examined with a binocular dissecting microscope for any visible aberrant characters which appeared useful as mutant markers. To establish pure mutant strain, continuous selections and inbreedings were performed for these mutant-like flies, and the mode of inheritance and linkage relationships of thus established mutants were studied by examining the segregation among the offspring from crossing experiments. In addition, a whiteeyed mutant strain was obtained from Mr. Y. Washizuka, Ihara Agric. Chem. Laboratory, Shimizu, and a yellow-eyed strain from Dr. S. Asahina, National Institute of Health, Tokyo, who had originally obtained it from the 406th Medical General Laboratory, Sagamihara.

For the crossing experiments, newly emerged virgin females were separated from males within 8 hours after the breeding jar had been cleared of any adult flies already emerged. Powdered milk and water were separately fed to adult flies. Mating, feeding and oviposition were obtained in cages measuring $10 \times 10 \times 12 \mathrm{~cm}^{3}$ or $20 \times 20$ $\times 20 \mathrm{~cm}^{3}$. The larval medium consisted of a mixture of 2 parts wheat bran, 1 part powdered fish, 1 part powdered mouse biscuit and 3 parts water; this was placed in a glass jar of about $650 \mathrm{ml}$. capacity and the eggs were inoculated. The jar was then covered with a piece of cotton cloth and placed in a rearing room maintained at $25^{\circ} \mathrm{C}$, at which temperature each jar yielded $100-500$ flies by the 10 th to 13th day.

\section{Results and Discussions}

\section{Mutant List}

Large numbers of morphologically aberrant flies were found to appear spontaneously in the field-collected strains. During the subsequent course of inbreeding and selection, many of them failed to become established because of their poor viability, penetrance and expressivity. However, 12 relatively good mutants have been isolated 
and established successfully in this laboratory. From the yellow-eyed strain, two eyecolor mutants were separated and proved to be allelic to the American ge (green) mutant and to the Italian ocra mutant, respectively. The white-eyed mutant was also allelic to the American $w^{57}$ (white-57) gene. Other eye-color mutants from Japanese strains, $b u$ (brunette) and do (dark orange), were not allelic to other American eye-color mutants examined, $r b$ (ruby), car (carnation) and $\mathrm{cm}$ (carmine). Other mutants affected the bristles, size or shape of wing, wing venation, shape of legs, etc. The following is a list of those mutants which became sufficiently established for use in linkage tests:

Abr: Abrupt Vein $\mathrm{L}_{5}$ shortened, usually just near posterior crossvein. Posterior wing margin smoothed without definite notch and/or slight spine at a point opposite the tip of $L_{5}$ (Fig. 2). Semidominant; expressivity and penetrance erratic. acv: anterior-crossveinless Anterior crossveins entirely absent (Fig. 3). Posterior crossvein normal. Veins $\mathrm{L}_{3}$ and $\mathrm{L}_{4}$ often interrupted at middle part. Shape of scutellum not triangular but rather rectangular, occasionally with the posterior margin flattened or incised medially as in the mutant en (engrailed) of Drosophila melanogaster. Penetrance, expressivity and viability good.

$b u$ : brunette Eye color translucent reddish brown. Combination of $d o ; b u$ gives more dilute eye-color than do or bu. Expressivity and penetrance good.

do: dark orange Eye color translucent dark orange or light reddish brown. Slightly lighter than $b u$, but difficult to distinguish from it. Expressivity and penetrance good.

$f_{s}$ : fasciculate Vein $\mathrm{L}_{4}$ with a knot of vein, extra vein or often fascicles at a posterior region of the vein after swinging forward (Fig. 5). Usually recessive, but often a small portion of the heterozygotes expresses the character as in the homozygotes.

$g e^{2}$ : green-2 Eye color diluted to greenish yellow at emergence, darkening with age to pale yellowish brown. Found as $g e^{2} ; o c r a^{c}$ flies from a yellow-eyed stock. Allelic to the original ge. Expressivity and penetrance good.

ocrac: ocra-crimson Eye color translucent deep red or crimson. Found in the yellow-eyed stock with $g^{2}$. Allelic to the original ocra. Expressivity and penetrance good.

pcv: posterior-crossveinless Posterior crossveins absent or broken (Fig. 4). Anterior crossvein normal. Expressivity variable but penetrance complete.

$r d$ : reduced Bristles and hairs of abdominal tergites and sternites reduced in number, particulary at the fourth and/or fifth sternites. Expressivity and penetrance not complete.

$R l$ : Rolled In homozygous condition, wings rolled up intensely (Fig. 7); body size somewhat smaller and body surface less polished than wild type. In heterozygous condition, expressivity rather irregular, wings curled up, turned up at tips, 


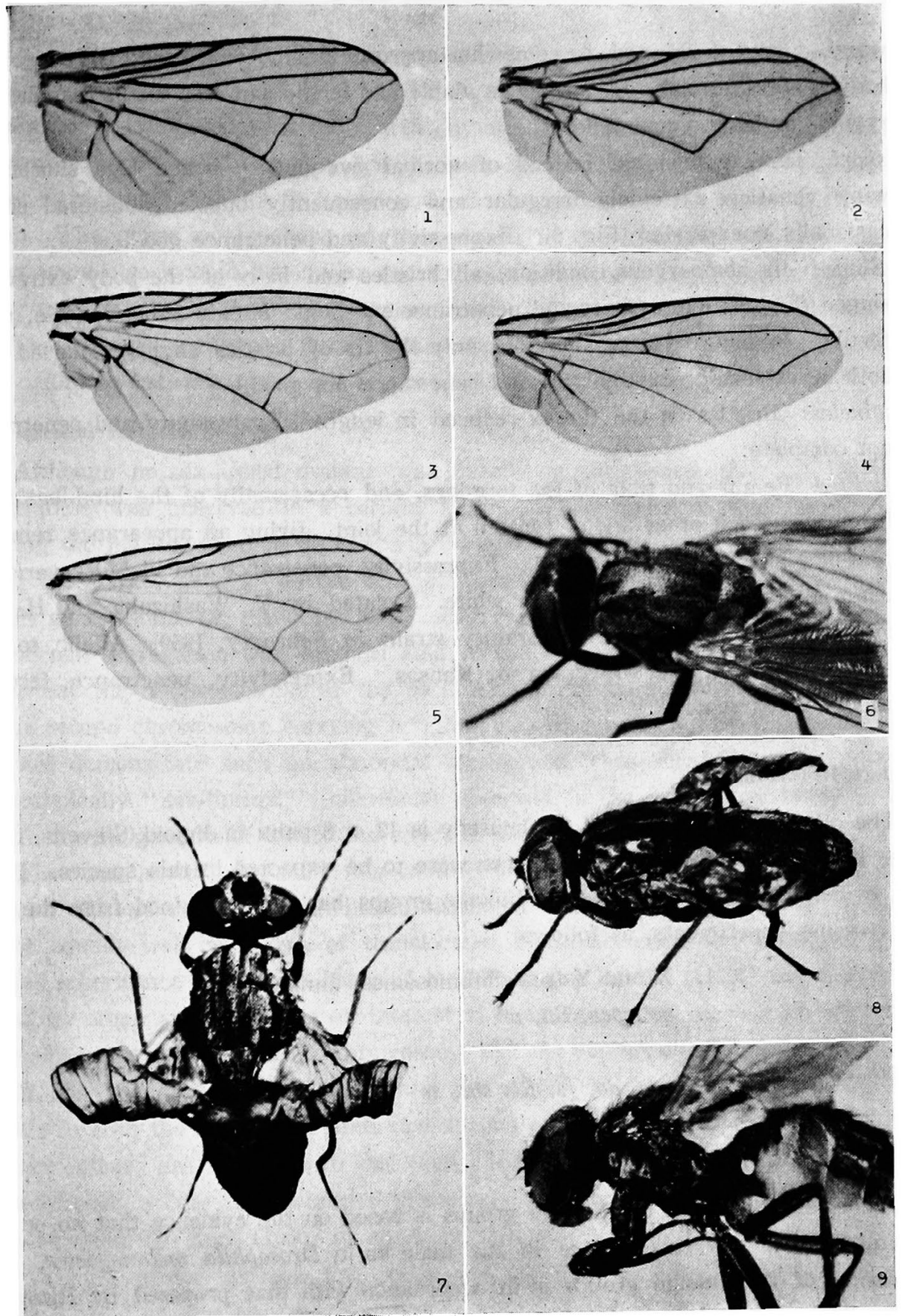

Figs. 1-5: Wing venations of wild and mutant strains of the housefly.

Figs. 6-9: Other mutants.

Fig. 1. + (Wild type).

3. acv (anterior-crossveinless).

5. fs (fasciculate).

7. $R l$ (Rolled wings).
2. Abr (Abrupt).

4. pcv (posterior-crossveinless).

6. $S n$ (Singed bristles).

8. sht (short tarsi).

9. $t w$ (twisted fore-legs). 
wavy, curved downward, or somewhat approaching the wild type; body size and body surface normal. Homozygotes viable and fertile, but less viable than heterozygotes or homozygous wild type.

sht: short Tarsi two-jointed instead of normal five-jointed, hence legs shortened; wing venation extremely irregular and consequently bubbled, blistered or occasionally unexpanded (Fig. 8). Expressivity and penetrance good.

$\mathrm{S} n$ : Singed In homozygous condition, all bristles and hairs of the body extremely singed (Fig. 6); expressivity and penetrance excellent; female almost sterile, male fertile. In heterozygous _condition, only the tip of bristles slightly gnarled and both sexes fertile; expressivity and penetrance not good.

ss: spineless Bristles on the thorax reduced in length. Expressivity and penetrance not complete.

$t w$ : twisted Femur and tibia of the fore-legs, and occasionally of the hind-legs also, fused with each other and/or twisted at the joint, giving an appearance reminiscent of a praying mantis (Fig. 9). Expressivity, penetrance and viability variable. $w^{3}$ : white-3 Eye color pale grayish white. Isolated by $\mathrm{Y}$. Washizuka and $\mathrm{H}$. Ikemoto from the Takatsuki Laboratory strain in February, 1959. Allelic to the mutant $w^{57}$ from the University of Kansas. Expressivity, penetrance, fertility and viability good.

\section{Linkage Relationshipg}

The chromosome number of the housefly is 12 or 6 pairs in diploid (Stevens, 1908; Perje, 1948), and hence 6 linkage groups were to be expected in this species. However, evidence for only 5 autosomal linkage groups has been obtained from the present crossing experiments, as follows:

1. X and $\mathrm{Y}$ (sex chromosomes, unmarked)

2. $g e^{2}, p c v, S n, w^{3}$

3. ocra $a^{c}$

4. $a c v, d o, f s, R l, s h t, s s$

5. bu, rd, tw

6. $A b r$

The establishment of the linkage groups is based on the evidence that no or few crossing-over, if any, takes place in the male as in Drosophila melanogaster. The numbering of the linkage groups is in accordance with that proposed by Hiroyoshi (1960). Perje (1948) had observed cytologically that most parts of the sex chromosomes were heterochromatic and hence predicted that sex-linked genes might be few or altogether lacking in the housefly. The fact no sex-linked mutant has yet been found in both Japanese and foreign strains supports her prediction.

The genes $g e^{3}$ and $w^{3}$ are located on the second chromosome because they are 
allelic to the American mutant genes already associated with that chromosome. Similarly, it is concluded that ocrac belongs to the third chromosome. When the mutant acv was crossed with the fourth chromosomal mutant $c t$ (cut) from America, no double recessive phenotype, $a c v c t$, was observed in the $\mathrm{F}_{2}$ generation. This evidence indicates that $a c v$ is linked with $c t$ and belongs to the fourth chromosomal group. The genes of Japanese origin assigned to the fifth and the sixth chromosomes were also located by similar crossing experiments with American mutants already associated with these chromosomes.

The order of arrangement of these mutant genes on each chromosome and the map-distances between them will be reported in a later publication.

\section{Sex-limited Inheritance}

Although no sex-linked mutant was found, an interesting case of sex-limited inheritance was observed in a certain strain. When males of a particular strain bearing the marker gene $b u$ on the fifth chromosome were crossed with females carrying the marker gene $w^{3}$ on the second chromosome, no $w^{3}$-type males appeared in the $\mathrm{F}_{2}$ generation. On the other hand, when $b u$ females were crossed with $w^{3}$ males, the normal segregation was demonstrated in the $F_{2}$ generation. Such evidence suggests that the $\mathrm{Y}$-chromosome of the $b u$ strain has become translocated or attached to the second chromosome carrying $w^{+}$gene. Similar crosses with another $b u$ strain did not demonstrate such an abnormal segregation, thus furnishing proof that the phenotypically "sex-limited" inheritance observed in the original bu strain was not due to the $b u$ gene itself but to the effect of the translocated Y-chromosome.

The "sex-linked" mutant $t$ (ala tumoscita) described by Sarkissian (1941) as follows: "blisters on wings; sex linked, lethal in homozygous condition in females", might equally well be a case of translocated Y-chromosome also. Instances of sexlimited inheritance have been reported by Milani and Franco (1959a) and Sullivan (in press) in other strains. It is of interest that as far as we know such phenomena take place only between the $\mathrm{Y}$-chromosome and the second chromosome.

It has been reported by Milani and Franco (1959b) that the genes for DDT-resistance in both the Italian and American strains of the housefly, which are not allelic to each other, are linked with $b w b$ and thus located on the second chromosome. More recently a case of sex-limited inheritance of the DDT-resistance character has been reported by Kerr (1960) in an Australian strain. From the above consideration, it could appear probable that in his Australian strain the DDT-resistance factor is also located on the second chromosome and that the Y-chromosome has become attached to it.

\section{Acknowledgement}

We are indebted to Prof. H. Kikkawa for his guidance, to Mr. T. Hiroyoshi for sending several marker strains and for his criticism, to Messrs. Y. Yamada, 
K. Takeda and Y. Wada for their assistance in crossing experiments, and to Misses Y. Miyashita and R. Nobuki for their laboratory assistance. Thanks are also due to Dr. S. Asahina and Mr. Y. Washizuka for furnishing the eye-color mutant strains, and to Dr. A. W. A. Brown, the University of Western Ontario, Canada, for his critical reading of the manuscript.

\section{Summary}

Fifteen visible mutants of the housefly have been isolated from Japanese populations and developed in marker strains suitable for further genetic investigation.

Although 6 linkage groups were to be expected from the known chromosome number, no sex-linked visible mutants were found, all the mutants being assignable to one or other of the 5 autosomal linkage groups.

In one strain the characteristic $w^{+}$of the second chromosome behaved as if it was sex-limited, it was suggested that the $\mathrm{Y}$-chromosome was occasionally translocated to the second chromosome.

\section{Literature cited}

Brown, A. W. A. 1958 Insecticide resistance in arthropods. 240 pp. Wld. Hlth. Org. Geneva. Crow, J. F. 1957 Genetics of insect resistance to chemicals. Ann. Rev. Ent. 2: 227-246.

Hiroyoshi, T. 1960 Some new mutants and linkage groups of the housefly. Jour. Econ. Ent. 53: $985-990$.

Kerr, R. W, 1960 Sex-limited DDT-resistance in houseflies. Nature, 185: 868.

Milani, R. 1954 The genetics of the housefly. Preliminary note. Atti IX Congr. Intern. Genet., Vol. Suppl. Caryologia: 791-796.

1955 Comportamento ereditario dei caratteri knock-down resistance (kdr) e plexus (plx) in Musca domestica L. Rend. Ist. Sup. Sanità, 18: 889-897.

- 1956-7 Ricerche genetiche sulla resistenza degli insetti alla azione delle sostanze tossiche. Riv. Parassit, 17: $223-246 ; 18: 43-60$.

1958 Report to Insect Toxicologist Inform. Serv. 1: 74-75.

and M. G. Franco 1959a Fertilità, rapporto-sessi e segregazione del mutante bwb in incroci tra ceppi geograficamente separati di Musca domestica L. Symp. Genet. 6: 249-268. and $1959 \mathrm{~b}$ Comportamento ereditario della resistenza al DDT in incroci tra il ceppo Orlando- $R$ e ceppi $k d r$ e $k d r^{+}$di $M u s c a$ domestica L. Symp. Genet. 6: 269-303. - and A. Travaglino 1957 Ricerche genetiche sulla resistenza al DDT in Musca domestica concatenazione del gene $k d r$ (knockdown-resistance) con due mutanti morfologici. Riv. Parassit. 18: 199-202.

Perje, A. M. 1948 Studies on the spermatogenesis in Musca domestica. Hereditas 34: 209-232.

Sarkissian, S. M. 1941 Report to Drosophila Inform. Serv. 15: 19.

Serebrovsky, A. S. 1941 Report to Drosophila Inform. Serv. 15: 19.

Stevens, N. M. 1908 A study of the germ-cells of certain Diptera. Jour. Exp. Zool. 5: 359-374.

Sullivan, R. L. Linkage and sex limitation of several loci in the housefly. Jour. Hered. (in press).

and T. Hiroyoshi 1960 A preliminary report on mutations in the housefly. Jour. Econ. Ent. 53: 213-215.

Tsukamoto, M., M. Ogaki, and H. Kobayashi 1957 Malaria control and development of DDT resistant insects in Hikone city. Jap. Jour. Sanit. Zool. 8: 118-122. 